\title{
Telomere Length in Leukocyte DNA in Gastric Cancer Patients and its Association with Clinicopathological Features and Prognosis
}

\author{
TOMOMITSU TAHARA ${ }^{1}$, SAYUMI TAHARA ${ }^{2}$, NORIYUKI HORIGUCHI ${ }^{1}$, TOMOHIKO KAWAMURA $^{1}$, \\ MASAAKI OKUBO $^{1}$, TAKAMITSU ISHIZUKA ${ }^{1}$, HYUGA YAMADA ${ }^{1}$, DAI YOSHIDA ${ }^{1}$, TAKAFUMI OHMORI ${ }^{1}$, \\ KOHEI MAEDA ${ }^{1}$, NARUOMI KOMURA ${ }^{1}$, HIROKAZU IKUNO ${ }^{1}$, YASUTAKA JODAI ${ }^{1}$, \\ TOSHIAKI KAMANO ${ }^{1}$, MITSUO NAGASAKA ${ }^{1}$, YOSHIHITO NAKAGAWA ${ }^{1}$, TETSUYA TUSKAMOTO ${ }^{2}$, \\ MAKOTO URANO ${ }^{2}$, TOMOYUKI SHIBATA ${ }^{1}$, MAKOTO KURODA ${ }^{2}$ and NAOKI OHMIYA ${ }^{1}$ \\ ${ }^{1}$ Department of Gastroenterology, Fujita Health University School of Medicine, Toyoake, Japan; \\ ${ }^{2}$ Department of Diagnostic Pathology I, School of Medicine, Fujita Health University, Toyoake, Japan
}

\begin{abstract}
Background/Aim: Telomere shortening in leukocytes has been thought to be associated with reduced immune response capacity and increased chromosome instability. Several studies indicate that telomere length in the peripheral blood leukocyte DNA can predict clinical outcome of several cancers. We evaluated the potential association between telomere shortening in the leukocyte DNA and clinicopathological features and prognosis of gastric cancer $(G C)$ in Japanese patients. Materials and Methods: Telomere length in leukocyte DNA was measured using quantitative real-time polymerase chain reaction (PCR) in 207 GC patients. The association between telomere length and clinicopathological features and prognosis was evaluated. Results: These short-telomere group was significantly associated with advanced stage $(p=0.015)$, worse overall survival (OS) and progression-free survival (PFS) ( $p=0.046$ and 0.026, respectively). The same group was also weakly associated with overall and peritoneal recurrences ( $p=0.052$ and 0.059 , respectively). Conclusion: Telomere shortening in leukocyte DNA is associated with advanced stage and poor prognosis of GC, which may reflect their reduced immune response capacity or increased chromosome instability.
\end{abstract}

Gastric cancer (GC) is one of the most common malignancies worldwide accounting for nearly 70,000 new cases and 650,000 deaths per year $(1,2)$. Improvements in early detection by screening have resulted in lower incidence rates in most

Correspondence to: Tomomitsu Tahara, 1-98 Dengakugakubo Kutsukake-cho, Toyoake, Aichi, 470-1192, Japan. Tel: +81 562939240, Fax: +81 562938300, e-mail: tomomiccyu@yahoo.co.jp

Key Words: Telomere shortening, leukocyte DNA, gastric cancer, prognosis, Japanese. parts of the world, while the treatment outcomes for patients who have advanced disease at diagnosis are still poor (3). Moreover, GC is heterogeneous tumor in its clinical course and prognosis. Identification of molecular markers, which precisely predict prognosis, would provide more appropriate clinical implementation reflecting their heterogeneity.

Telomeres consist of repetitive nucleotide sequences and an associated terminal protein complex that help avoid loss of chromosomal integrity (4). Telomere shortening in genomic DNA seems to reflect lifetime accumulative oxidative stress through environmental exposures $(5,6)$. Telomere shortening was also observed in human epithelial cancers due to the formation of complex non-reciprocal translocations and increased chromosome instability (7-10).

Previous studies have revealed shorter telomere lengths in the lymphocytes of individuals suffering from age-related diseases, including cancer (10). Since telomere shortening in leukocytes can reduce the immune response capacity (11) and can also induce chromosome instability (7-10), recent studies have focused on the role of leukocyte telomere length in the prediction of cancer risk and prognosis (12-15). In GC, telomere shortening in the leukocyte DNA has been associated with GC susceptibility and its poor prognosis (1618 ). We evaluated the potential association between telomere shortening in the leukocyte DNA and clinicopathological features and prognosis of GC in Japanese patients.

\section{Materials and Methods}

Study population, sample DNA extraction and relative telomere length measurement. We enrolled 207 patients with gastric cancer (GC), being treated at the Fujita Health University Hospital, Toyoake, Japan, from September 2004 to February 2008. The patient cohort consisted of 58 females and 149 males with a median age of 70 years (range=37-97). The Ethics Committee of Fujita Health University 
Table I. Primer sequences used in telomere length measurement.

\begin{tabular}{lll}
\hline Assay name & Forward primer sequence & Reverse primer sequence \\
\hline $\begin{array}{l}\text { Telomere } \\
\text { Beta-globin }\end{array}$ & CGGTTTGTTTGGGTTTGGGTTTGGGTTTGGGTTTGGGTT & GGCTTGCCTTACCCTTACCCTTACCCTTACCCTTACCCT \\
\hline
\end{tabular}

School of Medicine approved the protocol and written informed consent was obtained from all subjects. All GCs were diagnosed histologically. Of the GC patients, 168 underwent gastrectomy or endoscopic resection and 39 chemotherapy. Detailed information about anatomic location, histologic type, lymphatic or venal invasion, lymph node or other metastases, as well as peritoneal dissemination was also obtained using the criteria of the Japanese classification of gastric carcinoma (19). Overall survival (OS), defined as the time from gastrectomy/endoscopic resection or start of initial administration of chemotherapy to the date of cancer-related death, was determined for 187 patients. Progression-free survival (PFS), defined as the time from gastrectomy or start of initial administration of chemotherapy to the date of tumor progression or cancer-related death, was also determined in the same cases. Patients with no confirmation of progression or cancer-related death were censored at the date of the last objective tumor assessment.

Three milliliters of whole blood was collected from each participant in an EDTA tube and stored frozen until DNA extraction. Leukocyte DNA extraction was performed using a commercial kit (FlexiGene DNA Kit, QIAGEN, Hilden, Germany) and stored until processing for analysis. Relative telomere length was measured by comparing the abundance of telomeric template relative to a single-copy gene (T/S) by quantitative real-time polymerase chain reaction (qRT-PCR) as described previously (20), with some modifications. The primers used for the telomere and the single-copy gene, beta-globin, are listed in the Table I. qRT-PCR was carried out using the iTaq SYBR Green Supermix (Bio-Rad, Hercules, CA, USA) and the ABI Prism 7900HT Real-Time PCR System (Applied Biosystems, Carlsbad, CA, USA). Detailed PCR conditions were available from our other studies (21, 22). The telomere and the single-copy gene (beta-globin) were analyzed on the same plate to reduce inter-assay variability and all the measurements were performed in duplicate and averaged.

Statistical analysis. Relative telomere length in the leukocyte DNA among GC patients presented an approximately Gaussian distribution, with over-representation of cases with short telomere; the cut-off value (relative T/S ratio) for the definition samples with short and long telomere groups was set at 3.06. Continuous and categorical variables among the different groups were compared using the Student's $t$-test and the chi-square test, respectively. The association between telomere length and OS and PFS in GC patients was assessed using the Kaplan-Meier method and the log-rank test. A $p$-value $<0.05$ was considered statistically significant.

\section{Results}

Telomere length in the leukocyte DNA was successfully measured in all 207 patients with GC. We first investigated the association between telomere length with clinicopathological features of GC, such as age, gender, anatomic location,
Table II. Leukocyte telomere length and subtypes of gastric cancer (GC).

\begin{tabular}{|c|c|c|c|c|}
\hline Variables n $(\%)$ & Long group & $(\%)$ & Short group & $(\%)$ \\
\hline \multicolumn{5}{|c|}{ Total number of patients } \\
\hline Age $($ mean \pm SEM $)$ & $68.1 \pm 0.81$ & - & $69.7 \pm 1.07$ & - \\
\hline \multicolumn{5}{|l|}{ Gender ${ }^{\mathrm{a}}$} \\
\hline Female & 36 & 24.7 & 22 & 36.1 \\
\hline Male & 110 & 75.3 & 39 & 63.9 \\
\hline \multicolumn{5}{|l|}{ Location } \\
\hline Cardia & 5 & 2.8 & 4 & 5.7 \\
\hline Upper & 19 & 10.5 & 11 & 15.7 \\
\hline Middle & 110 & 60.8 & 39 & 55.7 \\
\hline Lower & 47 & 26 & 16 & 22.9 \\
\hline \multicolumn{5}{|l|}{ Stage ${ }^{b}$} \\
\hline Early & 94 & 64.4 & 29 & 46.8 \\
\hline Advanced & 52 & 35.6 & 33 & 53.2 \\
\hline \multicolumn{5}{|l|}{ Histologic type } \\
\hline Differentiated & 110 & 76.9 & 40 & 65.6 \\
\hline Undifferentiated & 28 & 19.6 & 16 & 26.2 \\
\hline Mixed & 5 & 3.5 & 5 & 8.2 \\
\hline \multicolumn{5}{|l|}{ Lymphatic invasion } \\
\hline Negative & 75 & 65.2 & 22 & 59.5 \\
\hline Positive & 40 & 34.8 & 15 & 40.5 \\
\hline \multicolumn{5}{|l|}{ Venous invasion } \\
\hline Negative & 86 & 74.8 & 28 & 75.7 \\
\hline Positive & 29 & 25.2 & 9 & 24.3 \\
\hline \multicolumn{5}{|c|}{ Lymph node metastasis } \\
\hline no & 105 & 72.9 & 39 & 67.2 \\
\hline $\mathrm{n}+$ & 39 & 27.1 & 19 & 32.8 \\
\hline \multicolumn{5}{|c|}{ Peritoneal disseminationa } \\
\hline Negative & 125 & 86.8 & 46 & 78 \\
\hline Positive & 19 & 13.2 & 13 & 22 \\
\hline \multicolumn{5}{|l|}{ Liver metastasis } \\
\hline Negative & 136 & 94.4 & 54 & 93.1 \\
\hline Positive & 8 & 5.6 & 4 & 6.9 \\
\hline \multicolumn{5}{|c|}{ Other distant metastasis } \\
\hline Negative & 136 & 94.4 & 53 & 91.4 \\
\hline Positive & 8 & 5.6 & 5 & 8.6 \\
\hline
\end{tabular}

Histological type was determined for 204 cases. Lymphatic and venous invasion was determined for 152 cases. Lymph node, liver and other distant metastasis was determined for 202 cases. Peritoneal dissemination was determined for 203 cases. ${ }^{\mathrm{a}} p=0.098 ;{ }^{\mathrm{b}} p=0.015$; Statistical analysis was performed by the chi-square test. SEM, standard error of the mean.

histologic type, lymphatic or venal invasion and lymph node or other metastases, as well as peritoneal dissemination (Table II). The analysis was performed dividing the cases into long and short groups according to the telomere length. Among all 

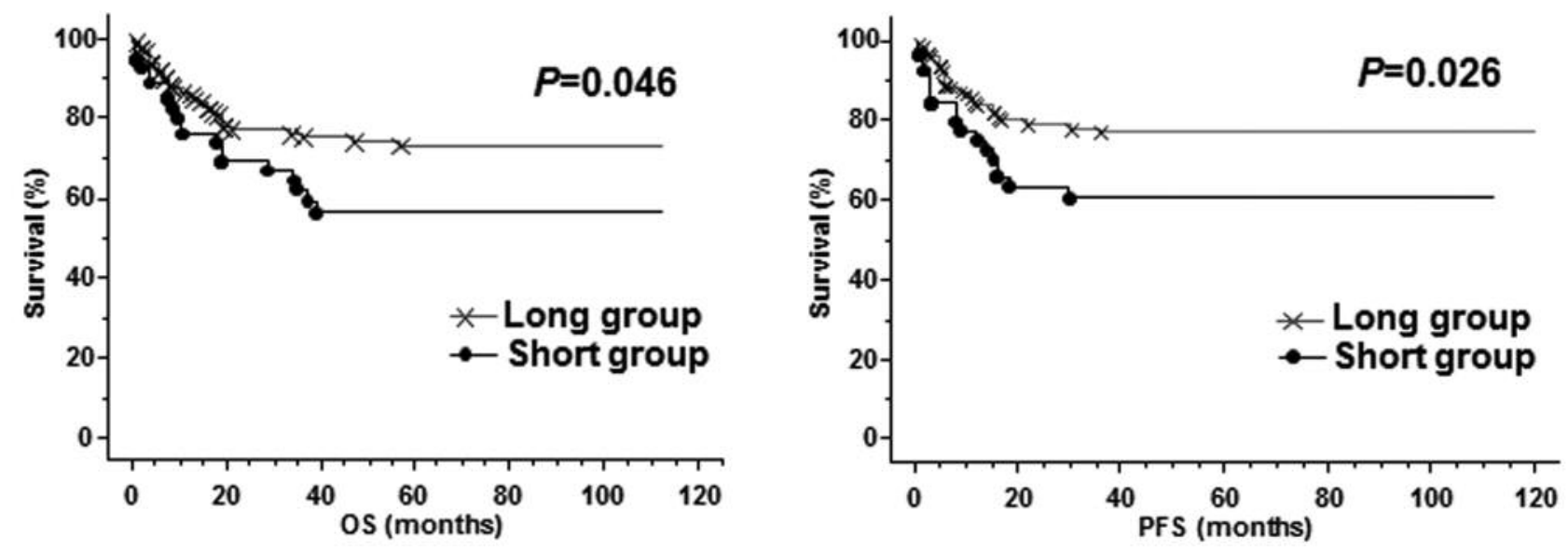

Figure 1. Association between telomere length, overall survival (OS, left) and progression-free survival (PFS, right) in gastric cancer patients. The difference between the two groups was assessed using the Kaplan-Meier method and the log-rank test.

clinicopathological features, we found that the short group was more frequent in the advanced stage than in early stage $(35.6 \%$ vs. $53.2 \%, p=0.015)$. We also found that the short group was weakly correlated with female patients $(36.1 \%$ vs. $24.7 \%$, $p=0.098$ ). For all other clinicopathological features, however, we did not find any significant association between telomere length and those clinicopathological features.

Next, we investigated whether the telomere length in the leukocyte DNA is associated with OS and PFS in GC patients. One hundred and eighty-seven patients were included in the analysis. We found that the short group was significantly associated with worse OS by the log-rank test $(p=0.046)$ (Figure 1). We also observed similar association between the short group with worse PFS by the same analysis $(p=0.026)$ (Figure 1$)$.

We also investigated the association between telomere length in the leukocyte DNA and recurrences of GC, including liver, peritoneal, lymph node and others. This analysis showed that the short group was weakly associated with the overall and peritoneal recurrences. $(p=0.052$ and 0.059 , respectively) (Table III).

\section{Discussion}

In the present study, we evaluated the potential association between telomere shortening in the leukocyte DNA and clinicopathological features and prognosis of GC in Japanese patients.

We found that patients with telomere shortening in the leukocyte DNA are associated with advanced stage GC and poor prognosis of both OS and RFS, suggesting that telomere length in the leukocyte DNA can serve as a prognostic factor for GC patients. Telomere shortening might lead to genomic
Table III. Association between leukocyte telomere length and recurrence in gastric cancer (GC) patients.

\begin{tabular}{|c|c|c|c|c|}
\hline Variables n (\%) & Long group & $(\%)$ & Short group & $(\%)$ \\
\hline Over all recurrences ${ }^{\mathrm{a}}$ & Long & & Short & \\
\hline Negative & 104 & 80 & 38 & 66.7 \\
\hline Positive & 26 & 20 & 19 & 33.3 \\
\hline \multicolumn{5}{|l|}{ Liver recurrences } \\
\hline Negative & 127 & 97.7 & 55 & 96.5 \\
\hline Positive & 3 & 2.3 & 2 & 3.5 \\
\hline \multicolumn{5}{|l|}{ Peritoneal recurrences ${ }^{b}$} \\
\hline Negative & 118 & 90.8 & 46 & 80.7 \\
\hline Positive & 12 & 9.2 & 11 & 19.3 \\
\hline \multicolumn{5}{|l|}{ Lymph node recurrences } \\
\hline Negative & 119 & 91.5 & 54 & 94.7 \\
\hline Positive & 11 & 8.5 & 3 & 5.3 \\
\hline \multicolumn{5}{|l|}{ Other recurrences } \\
\hline Negative & 118 & 90.8 & 53 & 93 \\
\hline Positive & 12 & 9.2 & 4 & 7 \\
\hline
\end{tabular}

Recurrence was determined for 187 cases. ${ }^{\mathrm{a}} p=0.052$ : ${ }^{\mathrm{b}} p=0.059$; Statistical analysis was performed by the chi-square test.

instability leading to cancer susceptibility and progression (10). Thus far, a number of studies have demonstrated that telomere length in the leukocyte DNA is associated with risk and prognosis of various types of cancers (12-15). In GC, association between short leukocyte telomere and cancer predisposition was demonstrated in two studies in the Chinese population $(16,17)$. It has also been reported that patients with short leukocyte telomere are associated with poor prognosis in the Chinese population (18). Taken together, our findings support an evidence that telomere shortening in the leukocyte DNA is associated with poor clinical outcomes in GC patients 
in a diverse population. Concerning the relationship between leukocyte telomere length and clinical outcomes of other cancer types, short telomere length was associated with poor clinical outcomes of colorectal cancer patients (15), while several studies reported that patients with longer telomere length have rather worse survival of certain types of cancers, including liver, breast and renal cancer (23-25). These discrepancies may reflect organ-specific role of leukocyte telomere length in cancer progression, which needs to be clarified in detail.

It has also been proposed that weakening of immune function is also an important potential biological mechanism for the association between short leukocyte telomere and poorer prognosis of cancer patients (26). The immune system is highly sensitive to shortening of telomeres as immunocompetence depends on cell renewal and growth of T- and B-cells (27). In GC patients, short leukocyte telomere length is associated with higher percentage of CD4+ T cells in peripheral blood mononuclear cells, which may be linked to reduced immune response capacity and poor prognosis (18). It is possible that short leukocyte telomere length might reflect inter-individual differences in immune response and influence the progression and prognosis of GC patients.

In this study, we measured telomere length in the DNA derived from peripheral blood, which is likely to reflect systemic genomic status rather that of primary GC tissues. Telomere length measured in easily accessible tissues, such as blood leukocytes, has been proposed as a potential biomarker for risk assessment and prognostication of malignancies (1218). However, the associations seen in our study were always marginal. Although we showed trends between short leukocyte telomere and overall and peritoneal recurrences, such an aptitude was not reached to a significant level. Our data suggest that true differences of leukocyte telomere length among relevant subtypes might be small but need careful attention as to sample size, validation and quantitation to avoid the possibilities of false-positive findings.

\section{Conflicts of Interest}

The Authors declare that they have no conflicts of interest.

\section{References}

1 Ferlay J, Bray F, Parkin DM, Pisani P, editors. Gobocan 2000: Cancer incidence and mortality worldwide (IARC Cancer Bases No. 5). Lyon: IARC Press; 2001.

2 Lau M, Le A and El-Serag HB: Noncardia gastric adenocarcinoma remains an important and deadly cancer in the United States: Secular trends in incidence and survival. Am J Gastroenterol 101: 2485-2492, 2006

3 Nashimoto A, Akazawa K, Isobe Y, Miyashiro I, Katai H, Kodera Y, Tsujitani S, Seto Y, Furukawa H, Oda I, Ono H, Tanabe S and Kaminishi M: Gastric cancer treated in 2002 in Japan: 2009 annual report of the JGCA nationwide registry. Gastric Cancer 16: 1-27, 2013.
4 de Lange T: The protein complex that shapes and safeguards human telomeres. Genes Dev 19: 2100-2110, 2005.

5 von Zglinicki T: Oxidative stress shortens telomeres. Trends Biochem Sci 27: 339-344, 2002.

6 Wu X, Amos CI, Zhu Y, Zhao H, Grossman BH, Shay JW, Luo S, Hong WK and Spitz MR: Telomere dysfunction: A potential cancer predisposition factor. J Natl Cancer Inst 95: 1211-1218, 2003.

7 Artandi SE, Chang S, Lee SL, Alson S, Gottlieb GJ, Chin L and DePinho RA: Telomere dysfunction promotes non-reciprocal translocations and epithelial cancers in mice. Nature 406: 641645, 2000.

8 Bailey SM and Murnane JP: Telomeres, chromosome instability and cancer. Nucleic Acids Res 34: 2408-2417, 2006.

9 Cheung $\mathrm{AL}$ and Deng W: Telomere dysfunction, genome instability and cancer. Front Biosci 13: 2075-2090, 2008.

10 Murnane JP: Telomere loss as a mechanism for chromosome instability in human cancer. Cancer Res 70: 4255-4259, 2010.

11 Effros RB: Telomere/telomerase dynamics within the human immune system: Effect of chronic infection and stress. Exp Gerontol 46: 135-140, 2011.

12 Hou L, Zhang X, Gawron AJ and Liu J: Surrogate tissue telomere length and cancer risk: Shorter or longer? Cancer Lett 319: 130-135, 2012.

13 Jang JS, Choi YY, Lee WK, Choi JE, Cha SI, Kim YJ, Kim CH, Kam S, Jung TH and Park JY: Telomere length and the risk of lung cancer. Cancer Sci 99: 1385-1389, 2008.

14 Shao L, Wood CG, Zhang D, Tannir NM, Matin S, Dinney CP and $\mathrm{Wu} \mathrm{X}$ : Telomere dysfunction in peripheral lymphocytes as a potential predisposition factor for renal cancer. J Urol 178 : 1492-1496, 2007.

15 Chen Y, Qu F, He X, Bao G, Liu X, Wan S and Xing J: Short leukocyte telomere length predicts poor prognosis and indicates altered immune functions in colorectal cancer patients. Ann Oncol 25: 869-876, 2014.

16 Hou L, Savage SA, Blaser MJ, Perez-Perez G, Hoxha M, Dioni L, Pegoraro V, Dong LM, Zatonski W, Lissowska J, Chow WH and Baccarelli A: Telomere length in peripheral leukocyte DNA and gastric cancer risk. Cancer Epidemiol Biomarkers Prev 18: 3103-3109, 2009.

17 Liu X, Bao G, Huo T, Wang Z, He X and Dong G: Constitutive telomere length and gastric cancer risk: Casecontrol analysis in Chinese Han population. Cancer Sci 100: 1300-1305, 2009.

18 Qu F, Li R, He X, Li Q, Xie S, Gong L, Ji G, Lu J and Bao G: Short telomere length in peripheral blood leukocyte predicts poor prognosis and indicates an immunosuppressive phenotype in gastric cancer patients. Mol Oncol 9: 727-739, 2015.

19 Japanese classification of gastric carcinoma: 3rd English edition. Japanese Gastric Cancer Association. Gastric Cancer 14: 101$112,2011$.

20 McGrath M, Wong JY, Michaud D, Hunter DJ and De Vivo I: Telomere length, cigarette smoking, and bladder cancer risk in men and women. Cancer Epidemiol Biomarkers Prev 16: 815819, 2007.

21 Tahara T, Shibata T, Kawamura T, Ishizuka T, Okubo M, Nagasaka M, Nakagawa Y, Arisawa T, Ohmiya N and Hirata I: Telomere length in non-neoplastic gastric mucosa and its relationship to $\mathrm{H}$. pylori infection, degree of gastritis, and NSAID use. Clin Exp Med 16: 65-71, 2016. 
22 Tahara T, Shibata T, Kawamura T, Horiguchi N, Okubo M, Nakano N, Ishizuka T, Nagasaka M, Nakagawa $\mathrm{Y}$ and Ohmiya $\mathrm{N}$ : Telomere length shortening in gastric mucosa is a field effect associated with increased risk of gastric cancer. Virchows Arch 469: 19-24, 2016.

23 Liu HQ, An JZ, Liu J, Yang YF, Zhang HX, Zhao BY, Li JB Yang HS, Chen ZN and Xing JL: Leukocyte telomere length predicts overall survival in hepatocellular carcinoma treated with transarterial chemoembolization. Carcinogenesis 33: 1040-1045, 2012.

24 Svenson U, Nordfjäll K, Stegmayr B, Manjer J, Nilsson P, Tavelin B, Henriksson R, Lenner P and Roos G: Breast cancer survival is associated with telomere length in peripheral blood cells. Cancer Res 68: 3618-3623, 2008.

25 Svenson U, Ljungberg B and Roos G: Telomere length in peripheral blood predicts survival in clear cell renal cell carcinoma. Cancer Res 69: 2896-2901, 2009.
26 Damjanovic AK, Yang Y, Glaser R, Kiecolt-Glaser JK, Nguyen $\mathrm{H}$, Laskowski B, Zou Y, Beversdorf DQ and Weng NP: Accelerated telomere erosion is associated with a declining immune function of caregivers of Alzheimer's disease patients. J Immunol 179: 4249-4254, 2007.

27 Hodes RJ, Hathcock KS and Weng NP: Telomeres in T and B cells. Nat Rev Immunol 2: 699-706, 2002.

Received February 6, 2017

Revised March 6, 2017

Accepted March 8, 2017 